\title{
Quantitative Determination Method for Trace Amount of Penicillin Contaminants in Commercially Available Drug Product by HPLC Coupled with Tandem Mass Spectrometry
}

\author{
Wataru TAKAdA, ${ }^{*, a}$ Toshikazu AdAchi, ${ }^{b}$ Noriaki Kinara, ${ }^{b}$ Satoshi KitAmura, ${ }^{a}$ Teruyuki KitAGaWA, ${ }^{a}$ \\ Masaki Mifune, ${ }^{c}$ and Yutaka SAITO ${ }^{c}$ \\ ${ }^{a}$ Analytical Research Laboratories, Fujisawa Pharmaceutical Co., Ltd.; ${ }^{b}$ Biopharmaceutical and Pharmacokinetic \\ Research Laboratories, Fujisawa Pharmaceutical Co., Ltd.; 2-1-6 Kashima, Yodogawa-ku, Osaka 532-8514, Japan: and \\ ${ }^{c}$ Faculty of Pharmaceutical Sciences, Okayama University; Tsushima-Naka, Okayama 700-8530, Japan. \\ Received August 30, 2004; accepted October 18, 2004
}

A quantitative determination method for trace amount of penicillin contaminants in an active pharmaceutical ingredient (API) has been developed. Selective extraction of penicillin contaminants from the matrix containing API and specific separation among penicillin contaminants were achieved through an on-line column switching technique with gradient elution, followed by tandem mass spectrometric determination. Validation was conducted on the developed method in terms of specificity, linearity, accuracy, precision, and detection limit, and appeared reasonable. The detection limit was estimated as $0.03 \mathrm{ng} / \mathrm{ml}$ or lower of the concentration of penicillin contaminants in the preparation, corresponding to 4 parts par billion (ppb) against the API. This fulfilled the regulatory requirement by the authorities.

Key words quantitative determination; penicillin contaminant; trace amount (ppb); commercially available drug product

The $\beta$-lactam antibiotics are one of the most well-known classes of drugs in the world. For a long period and still to date, they have been contributing to human health through treatment of bacterial infections of animals as well as of humans. On the other hand, it is anticipated that they have a potential to cause allergenic response, ${ }^{1)}$ to provoke multidrug-resistant strains of bacteria, ${ }^{2)}$ and to cause pathogen $\operatorname{load}^{3)}$ when applied into humans. As a result, the usage of the $\beta$-lactam antibiotics is strictly regulated by the authorities in the edible product industry and in the pharmaceutical industry. ${ }^{4-6)}$

Penicillin is classified as a $\beta$-lactam antibiotic by its chemical structure. In the pharmaceutical industry, one of the general concerns lies in the contamination of penicillins into non-penicillin products especially when the non-penicillin products are manufactured in the facility where penicillin was in use in the past. U.S. Food and Drug Administration publishes guidelines about this issue ${ }^{6)}$ and requests to test the presence of penicillin in the non-penicillin product if a reasonable contamination of penicillin exists. Therefore, it is essential to establish an analytical method for the detection of trace amount of penicillins on the occasion of manufacturing of non-penicillin products in the facility exposed to penicillin.

In-depth investigations have been made to detect trace amount of penicillins in milk, ${ }^{7}$ in tissues of animals ${ }^{8)}$ and in groundwater $\left.{ }^{9}\right)$ in order to prevent negative effects from penicillins in contamination. The sensitivity was reported at around parts per billion (ppb) against the material. On the contrary, there is no report about the detection of penicillin contamination by chemical methods in the pharmaceutical field since an active pharmaceutical ingredient (API) has relatively low molecular weight and is supposed to possess similar physicochemical properties with contaminants, resulting in a challenging situation to achieve appropriate quantification of the contaminants at a required level of $6 \mathrm{ppb}$ against API.

This paper describes an attempt to detect a trace amount of penicillin contaminants in a commercially available drug product through an on-line column switching technique followed by HPLC-MS/MS detection. Since the active pharmaceutical ingredient (API) in the product of concern is an amphiphilic compound, a couple of interesting observations were obtained during the investigations.

\section{Experimental}

Chemicals and Reagents Reference standards of penicillins (Amoxicillin, Ampicillin, and Flucloxacillin) were prepared by Fujisawa Pharmaceutical Co., Ltd. (Osaka, Japan). Funguard ${ }^{\mathbb{B}}$, which is a lyophilized drug product containing $75 \mathrm{mg}$ of Micafungin as an active pharmaceutical ingredient in one vial, was prepared by Fujisawa Pharmaceutical Co., Ltd. Micafungin drug substance was prepared by Fujisawa Pharmaceutical Co., Ltd. Acetonitrile (HPLC grade) was obtained from Wako Pure Chemical Industries Ltd. (Osaka, Japan). Trifluoroacetic acid (TFA) was obtained from Tokyo Kasei Kogyo Co., Ltd. (Tokyo, Japan).

Chromatographic Conditions Liquid chromatography was performed on an Agilent HPLC system 1100 series (Yokogawa Analytical, Japan), equipped with a switching valve. YMC-Pack NH2 $(10 \times 5 \mathrm{~mm}$ i.d., $5 \mu \mathrm{m}$ particle size, YMC Co., Ltd., Japan) and YMC-Pack ODS-AM $(150 \times 2 \mathrm{~mm}$ i.d., $5 \mu \mathrm{m}$ particle size, YMC Co., Ltd, Japan) were used in combination as column A and column B, respectively. The column temperature was controlled at $40{ }^{\circ} \mathrm{C}$. Mobile phase A was a mixture of water, acetonitrile, and TFA $(1000: 20: 1)$. Mobile phase B was a mixture of acetonitrile, water, and TFA $(800: 200: 1)$. A linear gradient condition was developed based on time $(t)$ after sample injection: $t=0-5 \mathrm{~min}, \% \mathrm{~B}=0 ; t=5-25 \mathrm{~min}$, linearly up to $\% \mathrm{~B}=45 ; t=25-35 \mathrm{~min}$, linearly up to $\% \mathrm{~B}=100$; and $t=35-40 \mathrm{~min}$, linearly down to $\% \mathrm{~B}=0 \%$. The flow rate was set at $0.2 \mathrm{ml} / \mathrm{min}$.

Mass Spectrometric Conditions Mass spectrometry was performed with an API3000 triple-quadrupole mass spectrometer (MDS Sciex, Canada), equipped with an electrospray ion source in the positive ion multiple reaction monitoring (MRM) mode. Zero air was used as the nebulizer gas, while nitrogen was used as the curtain gas and as the collision-induced dissociation (CID) gas. The electrospray voltage was $+5 \mathrm{kV}$. The selected protonated molecules at the first quadrupole (Q1) stage were subjected to CID with a collision energy of $13 \mathrm{~V}$ (Amoxicillin), $25 \mathrm{~V}$ (Ampicillin), and $21 \mathrm{~V}$ (Flucloxacillin), respectively.

Sample Preparation Approximately $1 \mathrm{ml}$ of water was added to one vial of Funguard $^{\mathbb{B}}$ to dissolve the contents. The solution was transferred into 
a $10-\mathrm{ml}$ volumetric flask and diluted with water to the volume to be used as the sample solution. Separately, $10 \mathrm{mg}$ each of penicillin reference standard, precisely weighed, was dissolved in water. The solution was diluted with water so that the final concentration of penicillin was $0.06 \mathrm{ng} / \mathrm{ml}$. This solution was used as the standard solution.

\section{Results and Discussion}

Amoxicillin, Ampicillin, and Flucloxacillin were the analytes determined to be contaminants in Funguard ${ }^{\circledR}$ developed for use of anti-fungal treatment by Fujisawa Pharmaceutical Co., Ltd., Japan. Figures 1 and 2 show the chemical structures of penicillin concerned and Micafungin, respectively. According to the guidance published by the U.S. Food and Drug Administration (FDA), the sensitivity for penicillin contaminants should be at 0.006 parts par million (ppm) against API. $^{10)}$

Commonly used techniques for the detection of trace amount of contaminants utilize the procedure of liquid-liquid extraction and/or solid phase extraction. However, such approaches did not work adequately for the recovery of the
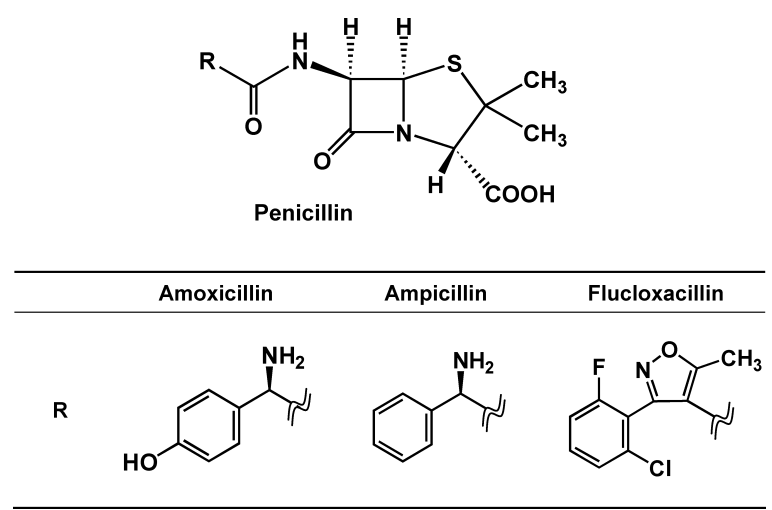

Fig. 1. Chemical Structure of Penicillins

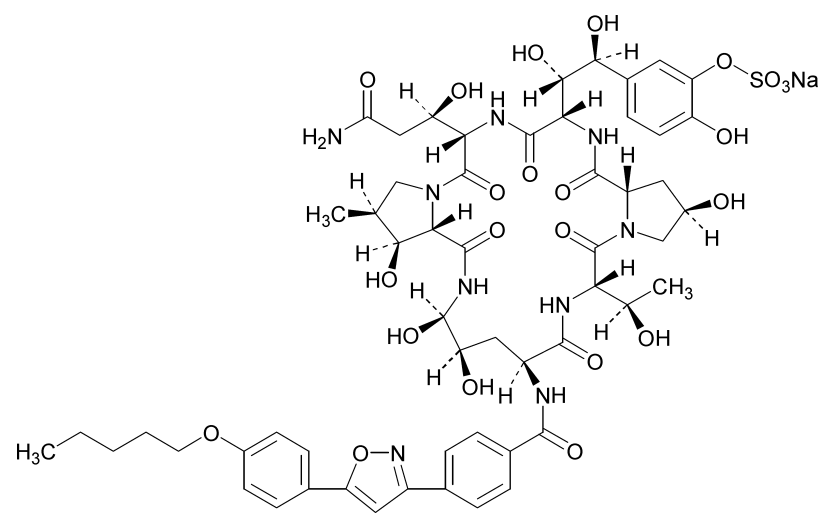

Fig. 2. Chemical Structure of Micafungin

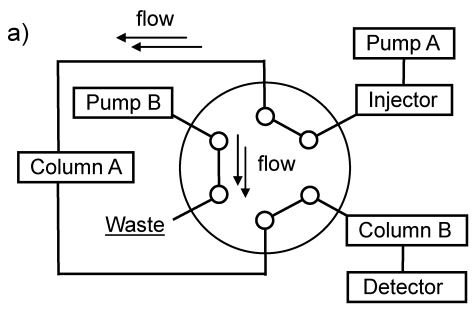

penicillins from the matrix containing Micafungin (poor recovery rate up to $40 \%$, data not shown), and careful attention was required to handle a trace amount of the penicillins during the extraction procedure. To improve the accuracy of the method without extraordinary handling, an on-line extraction was examined using the column switching technique, ${ }^{11-14)}$ which enables reduction of the loss of analytes during the extraction procedure.

Figure 3 shows diagrams of an HPLC equipped with a valve for the column switching technique. In general, the analytes are introduced into an HPLC system together with the other excipients through an injector and pumped out by Pump A (Fig. 3a). At Column A, unnecessary excipients are trapped, resulting in the specific extraction of the analytes from the matrix of the excipients. Then, the position of the switching valve is changed (Fig. 3b) and the analytes are determined without interference from the unnecessary excipients. During the detection of the analytes, the unnecessary excipients trapped at Column A are flushed out from the HPLC system by Pump B. Sequential analysis is achievable after changing the switching valve back to its original position (Fig. 3a).

In this particular case of the detection of penicillin contaminants in Micafungin, the column of YMC-Pack NH2 yielded a successful extraction of the penicillins from the matrix containing Micafungin as Column A, and YMC-Pack ODS-AM was used for the separation among the penicillins as Column B.

After an adequate extraction/separation, trace amounts of penicillin contaminants were subjected to mass spectrometric detection with an electrospray ion source in the positive ion multiple reaction monitoring (MRM) mode. ${ }^{15-17)}$ Parameters of the mass spectrometer were investigated to maximize the intensity of the product ion. The peaks of $\mathrm{m} / \mathrm{z} 349.1$ for Amoxicillin, $m / z 106.2$ for Ampicillin, and $m / z 160.2$ for Flucloxacillin were found to show the highest intensity among several product ions. Table 1 summarizes the ion reactions of the penicillins and the collision energy used for the reaction. Figure 4 shows a postulated fragmentation pattern of each penicillin.

During the investigation, a couple of interesting observations were obtained.

1. A Split of the Penicillin Peak in the Presence of Micafungin: In proportion to increase in the concentration of Micafungin in the preparation, the penicillin peak became broader (Fig. 5b), and was finally observed as two peaks in the chromatograms as shown in Fig. 5 ( $5 c$ and d). This was not observed in the absence of Micafungin (Fig. 5a). It was assumed that penicillins could possibly be distributed not only to the stationary phase of the column, but to the Mica-

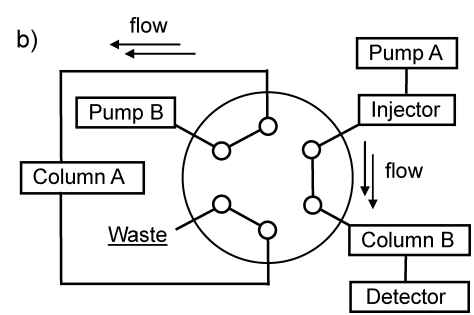

Fig. 3. Diagram of On-Line Separation by the Column-Switching Technique a) Loading and extraction of the analytes from the matrix, b) separation among the analytes and flushing out of the rest of the matrix from the system. 
fungin adsorbed on that stationary phase as well. In order to obtain a single penicillin peak, a gradient elution appeared necessary to pursue the on-line concentration of penicillins at the inlet port of Column B.

2. Poor Recovery of Flucloxacillin in the Presence of Micafungin: During a recovery study of the three types of penicillin from the matrix containing Micafungin, Flucloxacillin was not successfully recovered, in contrast to the case of Amoxicillin and Ampicillin. Micafungin is known as an amphiphilic compound and has the capability of micelle

Table 1. Ion Reaction and Collision Energy for MRM

\begin{tabular}{lccc}
\hline \hline Compound & Q1 m/z & Q3 m/z & $\begin{array}{c}\text { Collision } \\
\text { energy }(\mathrm{eV})\end{array}$ \\
\hline Amoxicillin & 366.0 & 349.1 & 13 \\
Ampicillin & 350.1 & 106.2 & 25 \\
Flucloxacillin & 454.1 & 160.2 & 21 \\
\hline
\end{tabular}
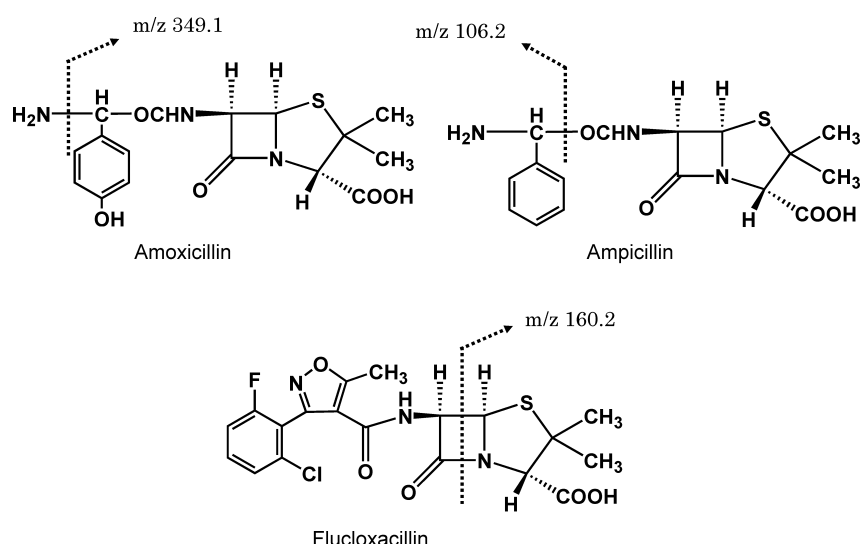

Fig. 4. Postulated Fragmentation Patterns of Amoxicillin, Ampicillin, and Flucloxacillin
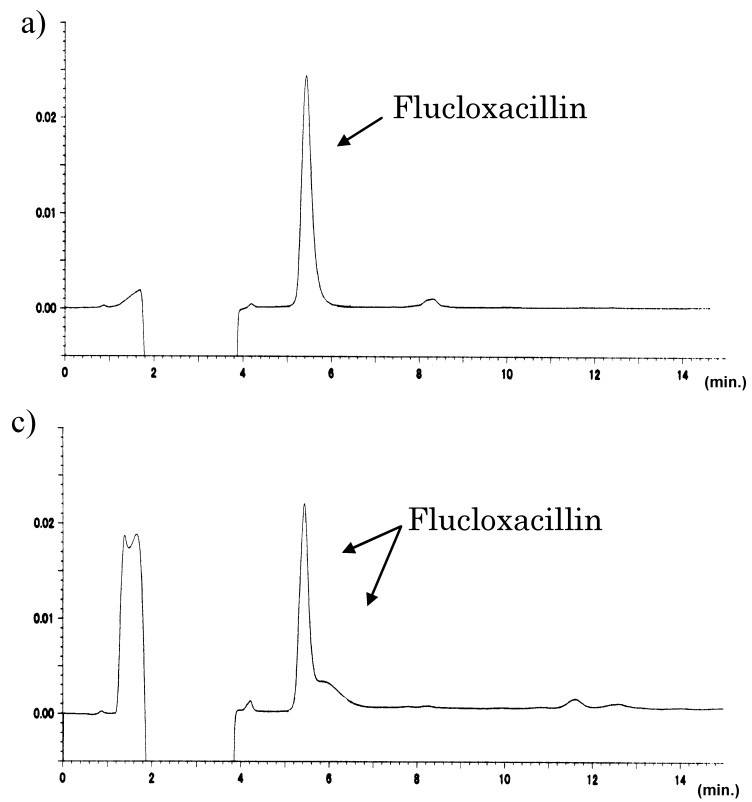

formation. Investigation indicated that a part of Flucloxacillin was captured in a micelle of Micafungin and could be released by increase in the proportion of acetonitrile in the mobile phase.

Finally, the method was designed as follows. During the first $5 \mathrm{~min}$ under $100 \%$ of mobile phase A (water/acetonitrile/TFA $=1000: 20: 1$ ), Amoxicillin and Ampicillin pass through Column A and are concentrated at the inlet port of Column B. Then, mutual separation is done during the following minutes under the established gradient condition. Flucloxacillin is gradually eluted from Column A separately from the other two penicillins, concentrated at the inlet of Column B, and subjected to MS detection. A sample solution is prepared by dissolving one vial of Funguard ${ }^{\circledR}$ into $10 \mathrm{ml}$ of water. Standard preparation is done by dissolving the reference standard of each penicillin in water, followed by dilution to obtain a concentration of $0.06 \mathrm{ng} / \mathrm{ml}$. Quantification is made by comparing the peak area of each penicillin from the sample solution with that from the standard solution.

Validation of the above established method was made according to the ICH guidelines ${ }^{18,19)}$ in terms of specificity, linearity, accuracy, precision (repeatability and intermediate precision), and detection limit.

Specificity Specificity was demonstrated by the following chromatograms. Figures $6 \mathrm{a}$ and $\mathrm{b}$ show the chromatograms of the standard solution (concentration of penicillin was $0.06 \mathrm{ng} / \mathrm{ml}$ ) and the sample solution prepared by dissolving one vial of Funguard ${ }^{\circledR}$ into water. The discrimination of the analytes was confirmed.

Linearity Linearity was evaluated by a plot of signals as a function of analyte concentration in the range from 50 to $150 \%$ of the target concentration $(0.03-0.09 \mathrm{ng} / \mathrm{ml})$. Good correlation coefficients of the regression line of 0.997 for Amoxicillin, 0.998 for Ampicillin, and 0.999 for Flucloxacillin were obtained across the range examined.

Accuracy Accuracy was assessed by a recovery percent-
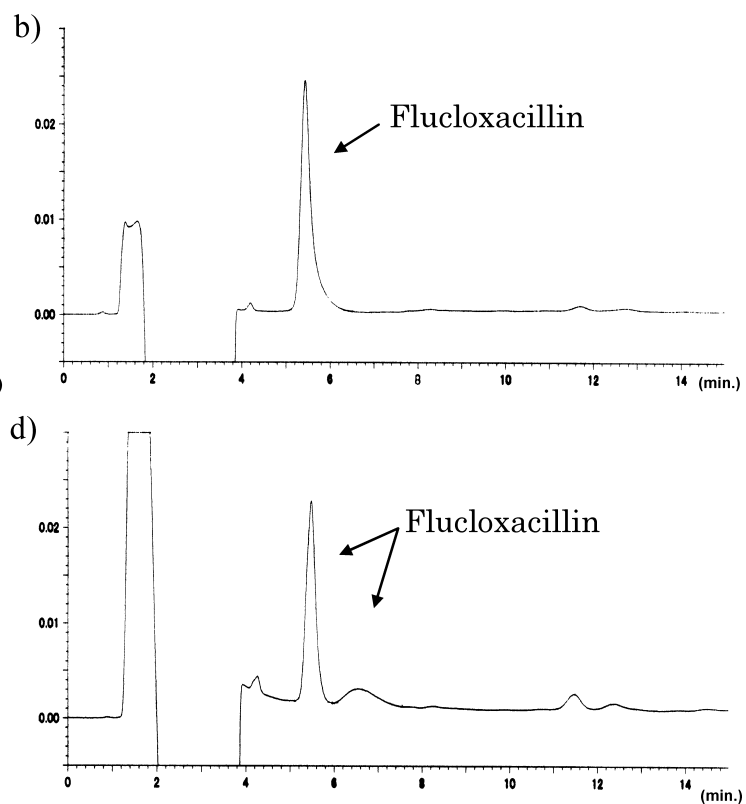

Fig. 5. Chromatograms of Flucloxacillin in the Presence/Absence of Micafungin

Concentrations of Flucloxacillin/Micafungin were: a) $200 \mathrm{ng} / \mathrm{ml}$ (absence of Micafungin), b) $200 \mathrm{ng} / 2.5 \mathrm{mg} / \mathrm{ml}$, c) $200 \mathrm{ng} / 5 \mathrm{mg} / \mathrm{ml}$, d) $200 \mathrm{ng} / 10 \mathrm{mg} / \mathrm{ml}$. HPLC conditions: Detector; an ultraviolet absorption photometer (wavelength: $220 \mathrm{~nm}$ ), HPLC column; Wakosil 5NH2 (150×4.6 mm i.d., $5 \mu \mathrm{m}$ particle size, Wako Pure Chemical Industries Ltd., Japan), column temperature; controlled at $40^{\circ} \mathrm{C}$, mobile phase; a mixture of water, acetonitrile, and TFA $(900: 100: 1)$, flow rate; $1.0 \mathrm{ml} / \mathrm{min}$. 


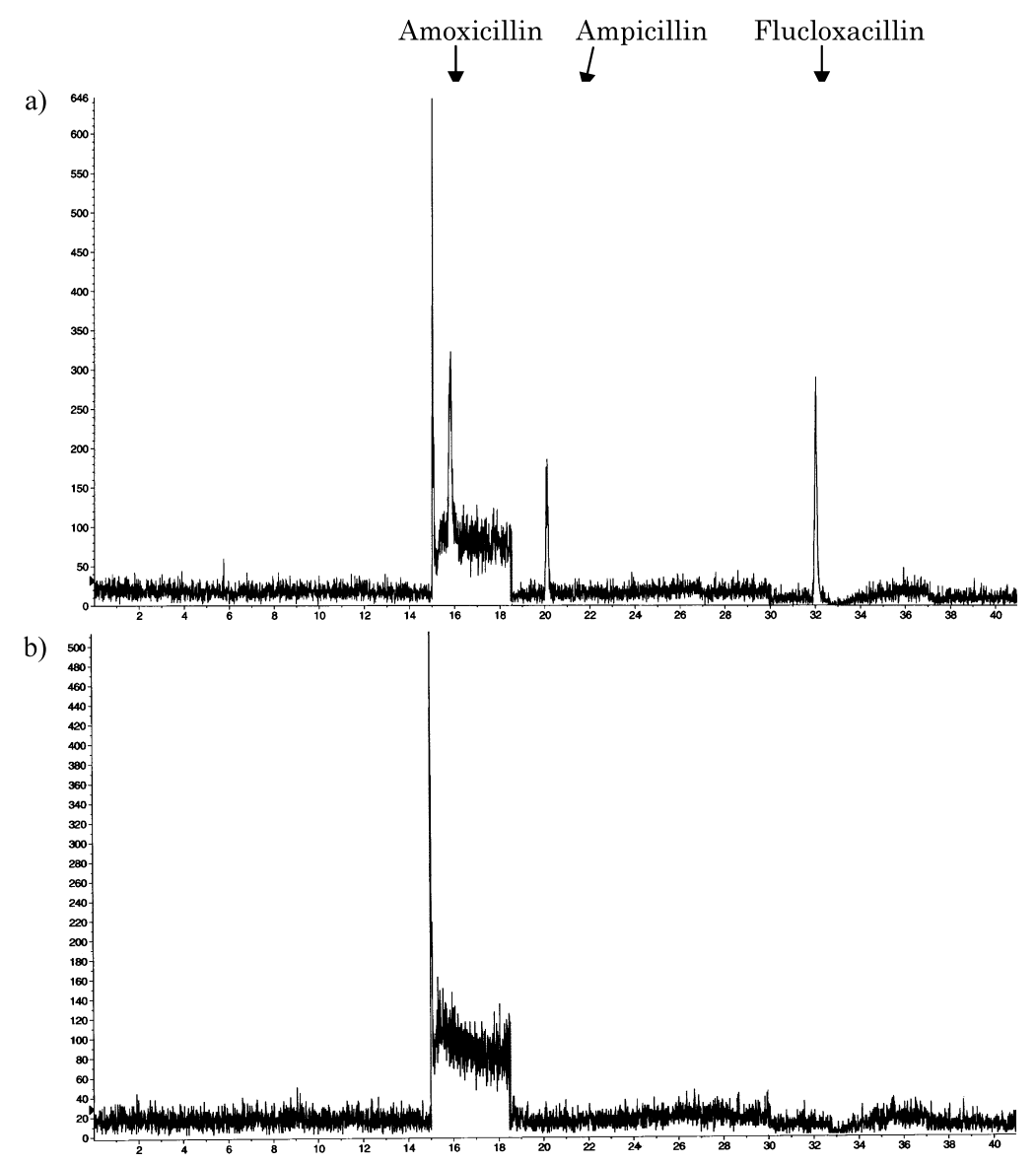

Fig. 6. Chromatograms of a) Standard Solution, b) Sample Solution

age of three penicillins in 9 determinations at the level of $75 \%, 100 \%$, and $125 \%$ of the target concentration (3 preparations for each of $0.045 \mathrm{ng} / \mathrm{ml}, 0.06 \mathrm{ng} / \mathrm{ml}$, and $0.075 \mathrm{ng} / \mathrm{ml}$ ) using one vial of Funguard ${ }^{\mathbb{B}}$ spiked with the corresponding amounts of analytes. All the results lay in the range between $90 \%$ and $113 \%$. The relative standard deviations (RSD) for the 9 determinations were $4.8 \%$ for Amoxicillin, 4.7\% for Ampicillin, and 5.3\% for Flucloxacillin. Sufficient accuracy of more than $85 \%$ of recovery and less than $10 \%$ of RSD was obtained for all of the penicillin analytes in the range examined.

Precision 1) Repeatability: Repeatability was evaluated by a relative standard deviation of 6 determinations using 6 vials of Funguard ${ }^{\circledR}$, each spiked with the analytes at the level of $100 \%$ of the target concentration $(0.06 \mathrm{ng} / \mathrm{ml})$. The RSDs of 5.5\% for Amoxicillin, 2.2\% for Ampicillin, and 3.3\% for Flucloxacillin were obtained. A good repeatability of less than $10 \%$ was obtained for any type of penicillin.

2) Intermediate Precision: Intermediate precision was assessed in focus of day-to-day variation by using the results for accuracy as Day 1 and those for repeatability as Day 2, respectively. The relative standard deviations of 15 determinations in total were obtained as $4.9 \%$ for Amoxicillin, $4.4 \%$ for Ampicillin, and 5.3\% for Flucloxacillin, as shown in Table 2. All of them lay well within the range of less than $10 \%$.

Detection Limit Based on a signal-to-noise ratio $(\mathrm{S} / \mathrm{N})$ from the standard solution according to the prescription in the European Pharmacopoeia, detection limit was determined
Table 2. Intermediate Precision (Day-to-Day Variation)

\begin{tabular}{cl}
\hline \hline Analyte & \multicolumn{1}{c}{ Parameter } \\
\hline Amoxicillin & Average: $96.7 \%$ \\
& S.D.: 4.77 \\
\multirow{3}{*}{ Ampicillin } & R.S.D. $4.9 \%(n=15)$ \\
& Average: $100.5 \%$ \\
Flucloxacillin & S.D.: 4.39 \\
& R.S.D. $4.4 \%(n=15)$ \\
& Average: $100.6 \%$ \\
& S.D.: 5.33 \\
& R.S.D. $5.3 \%(n=15)$ \\
\hline
\end{tabular}

as $0.033 \mathrm{ng} / \mathrm{ml}$ for Amoxicillin, $0.008 \mathrm{ng} / \mathrm{ml}$ for Ampicillin, and $0.006 \mathrm{ng} / \mathrm{ml}$ for Flucloxacillin, corresponding to $4 \mathrm{ppb}$, $1 \mathrm{ppb}$, and $0.7 \mathrm{ppb}$ against Micafungin, respectively.

Six lots of Funguard ${ }^{\circledR}$ were examined using the developed test method and yielded a peak response below the limit of detection. These results proved that the level of penicillin contaminants in the samples tested were less than $4 \mathrm{ppb}$ for Amoxicillin, $1 \mathrm{ppb}$ for Ampicillin, and $0.7 \mathrm{ppb}$ for Flucloxacillin, respectively.

\section{Conclusion}

A quantitative determination method for trace amount of penicillin contaminants in a commercially available drug product has been established. Quantification was achievable at the level of $0.06 \mathrm{ng} / \mathrm{ml}$ for three kinds of penicillins: Amoxicillin, Ampicillin, and Flucloxacillin. Validation of the 
established method was made and shown to be reasonable. The detection limit indicated the capability of the method to detect penicillin contaminants at a level less than $4 \mathrm{ppb}$ against the API. This fulfilled the regulatory requirements by the authorities. It can be concluded that the developed method has higher selectivity and sensitivity than other reported methods in the pharmaceutical field.

\section{References}

1) Torres M. J., Mayorga C., Pamies R., Rodriquez J. L., Juarez C., Romano A., Blanca M., Allergy, 54, 936-943 (1999).

2) Ball P., Baquero F., Cars O., File T., Garau J., Klugman K., Low D. E., Rubinstein E., Wise R., and The Consensus Group on Resistance and Prescribing in Respiratory Tract Infection, J. Antimicrob. Chemother., 49, 31- 40 (2002).

3) Consideration of the Human Health Impact of the Microbial Effects of Antimicrobial New Animal Drugs Intended for Use in Food-Producing Animals, Guidance for Industry 78, U.S. Food and Drug Administrations, December 1999.

4) Penicillins Summary Report, Council Regulation No. 2377/90, Committee for Veterinary Medicinal Products, The European Agency for the Evaluation of Medicinal Products.

5) Tolerance for Residues of New Animal Drugs in Food, Code of Federal Regulations, Title 21, Part 556, U.S. Food and Drug Administration.

6) Current Good Manufacturing Practice for Finished Pharmaceuticals, Code of Federal Regulations, Title 21, Part 211, U.S. Food and Drug Administration.
7) Heller D. N., Ngoh M. A., Rapid Commun. Mass Spectrom., 12, 2031-2040 (1998).

8) Ito Y., Ikai Y., Oka H., Matsumoto H., Kagami T., Takeba K., J. Chromatogr. A, 880, 85-91 (2000).

9) Sacher F., Lange F. T., Brauch H.-J., Blankenhorn I., J. Chromatogr. A, 938, 199-210 (2001).

10) Human Drug Cgmp Notes, U.S. Food and Drug Administration, Volume 8, Number 3, September 2000.

11) Boppana V. K., Miller-Stein C., Schaefer W. H., J. Chromatogr. B, 678, 227-236 (1996)

12) van der Hoeven R. A. M., Hofte A. J. P., Frenay M., Irth H., Tjaden U. R., van der Greef J., Rudolphi A., Boos K.-S., Varga G. M., Edholm L. E., J. Chromatogr. A, 762, 193-200 (1997).

13) Needham S. R., Cole M. J., Fouda H. G., J. Chromatogr. B, 718, 8794 (1998).

14) Beaudry F., Le Blanc J. C. Y., Coutu M., Brown N. K., Rapid Commun. Mass Spectrom., 12, 1216-1222 (1998).

15) Straub R., Linder M., Voyksner R. D., Anal. Chem., 66, 3651-3658 (1994).

16) Crommentuyn K. M. L., Rosing H., Nan-Offeringa L. G. A. H., Hillebrand M. J. X., Huitema A. D. R., Beijnen J. H., J. Mass Spectrom., 38, $157-166$ (2003).

17) Lausecker B., Fischer G., J. Mass Spectrom., 38, 649-658 (2003).

18) Text on Validation of Analytical Procedures, International Conference on Harmonization of Technical Requirements for Registration of Pharmaceuticals for Human Use, Q2A.

19) Validation of Analytical Procedures: Methodology, International Conference on Harmonization of Technical Requirements for Registration of Pharmaceuticals for Human Use, Q2B. 